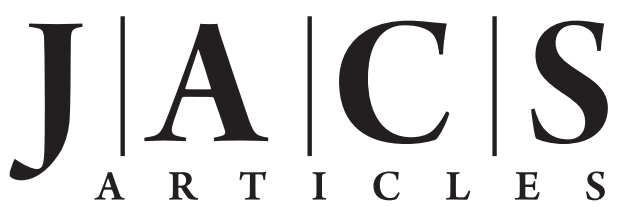

Published on Web 07/12/2010

\title{
Chemical Imaging of Catalyst Deactivation during the Conversion of Renewables at the Single Particle Level: Etherification of Biomass-Based Polyols with Alkenes over H-Beta Zeolites
}

\author{
Andrei N. Parvulescu, ${ }^{\dagger}$ Davide Mores,${ }^{\dagger}$ Eli Stavitski, ${ }^{\dagger}$ Cristian M. Teodorescu, ${ }^{\ddagger}$ \\ Pieter C. A. Bruijnincx, ${ }^{\dagger}$ Robertus J. M. Klein Gebbink, ${ }^{\S}$ and Bert M. Weckhuysen ${ }^{\star \dagger}$ \\ Inorganic Chemistry and Catalysis Group, Debye Institute for Nanomaterials Science, Utrecht \\ University, Sorbonnelaan 16, 3508 TB Utrecht, The Netherlands, The National Institute of \\ Materials Physics, Atomistilor Str. 105bis, PO Box MG. 7, 077125 Magurele-Bucharest, \\ Romania, and Organic Chemistry and Catalysis Group, Debye Institute for Nanomaterials \\ Science, Utrecht University, Padualaan 8, 3584 CH Utrecht, The Netherlands
}

Received March 26, 2010; E-mail: b.m.weckhuysen@uu.nl

\begin{abstract}
The etherification of biomass-based alcohols with various linear $\alpha$-olefins under solvent-free conditions was followed in a space- and time-resolved manner on $9 \mu \mathrm{m}$ large $\mathrm{H}$-Beta zeolite crystals by confocal fluorescence microscopy. This allowed us to visualize the interaction with the substrate and distribution of the coke products into the catalyst at the level of an individual zeolite crystal during the etherification process. The spectroscopic information obtained on the micrometer-scale zeolite was in line with the results obtained with bulk characterization techniques and further confirmed by the catalytic results obtained both for micrometer-scale and nanoscale zeolites. This allowed us to explain the influence of the substrate type (glycerol, glycols, and alkenes) and zeolite properties (Si/Al ratio and particle size) on the etherification activity. The etherification of the biomass-based alcohols takes place mainly on the external surface of the zeolite particles. The gradual blockage of the external surface of the zeolite results in a partial or total loss of etherification activity. The deactivation could be attributed to olefin oligomerization. The high conversions obtained in the etherification of 1,2-propylene glycol with long linear alkenes (up to $80 \%$ ) and the pronounced deactivation of the zeolite observed in the etherification of glycerol with long linear alkenes ( $\max .20 \%$ conversion) were explained by the spectroscopic measurements and is due to differences in the adsorption, i.e., in the center of the zeolite particle for glycerol and on the external surface in the case of glycols.
\end{abstract}

\section{Introduction}

Deactivation due to coke formation is a very important topic in acid heterogeneous catalysis, for zeolites in particular. ${ }^{1}$ Heavy byproducts are usually formed during the catalytic reaction and cover the active sites or block the pore network of the zeolite, resulting in partial or total loss of catalytic activity. Several studies were devoted to zeolite deactivation during large-scale processes, e.g., cracking of heavy petroleum fractions or the methanol-to-olefin (MTO) process. ${ }^{1,2}$ In these cases, the formation of coke was associated with olefin side reactions and with processes that take place at high temperatures $\left(>250{ }^{\circ} \mathrm{C}\right)$, mostly in fixed bed reactors. Few examples of zeolite deactivation due to coke formation in the liquid phase at low temperatures were also reported and assigned to similar olefin side reactions. Under

\footnotetext{
$\dagger$ Inorganic Chemistry and Catalysis Group, Debye Institute.

$\div$ The National Institute of Materials Physics.

$\S$ Organic Chemistry and Catalysis Group, Debye Institute.

(1) Karge, H. G. In Introduction to Zeolite Science and Practice, 2nd ed.; van Bekkum, H., Flanigen, E. M., Jacobs, P. A., Jansen, J. C. Eds.; Elsevier: New York, 2001; pp 707-746.

(2) (a) Guisnet, M.; Magnoux, P. Appl. Catal. 1989, 54, 1-27. (b) Froment, G. F. Catal. Rev. 2008, 50, 1-18.
}

these conditions olefins are typically transformed to coke via dimerization, cracking, alkylation, or cyclization reactions. ${ }^{1,3,4}$

Since coke formation invariably implies loss of valuable organic substrates and requires high energy costs for catalyst regeneration, significant emphasis has been put over time on the understanding of the mechanism of its formation. The identification of the steps controlling the polymerization of the olefins on various acid catalysts was believed to provide solutions to avoid coke generation. Subsequently, a number of routes were already proposed to minimize coke formation over zeolites, such as changing the reaction conditions, the use of solvents or an inert gas, and even optimization of the zeolite structure. ${ }^{1,2}$ Furthermore, the change in structure of the chemical feedstock upon the transition from the low functionality of petroleum-based feeds to the rich functionality of biomass-based feedstock may likely give rise to new challenges in developing more stable catalysts. Also, since many of the reactions involving biomass feedstock and biomass-derived platform molecules take place at relatively low temperatures and in the

(3) (a) Guisnet, M.; Magnoux, P. Appl. Catal., A 2001, 212, 83-96. (b) Bartholomew, C. H. Appl. Catal. A 2001, 212, 17-60.

(4) Guisnet, M. J. Mol. Catal. A: Chem. 2002, 182-183, 367-382. 
Scheme 1. Etherification of 1,2-Propylene Glycol (1,2PG) with 1-Octene over an Acid Catalyst, Such As Zeolite H-Beta

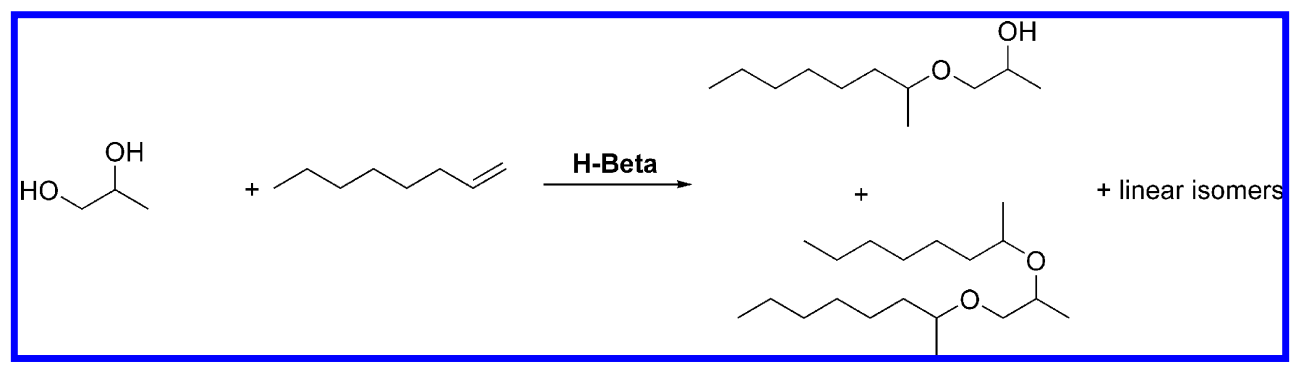

liquid phase, ${ }^{5}$ the understanding of the coke formation processes at these temperatures is of increasing importance.

The processes leading to zeolite deactivation have been followed by both in situ and ex situ spectroscopic techniques, ${ }^{6}$ gravimetric and thermogravimetric analysis (TEOM, TGA coupled with mass-spectrometry), and extraction and chemical analysis of the coke. ${ }^{7-9}$ However, despite the valuable data that these techniques have provided, they gave average information over a range of catalyst particles. Therefore, there is a lack of information regarding the reaction processes taking place at the molecular level or individual catalyst particles.

Recently, new microspectroscopic techniques, i.e., optical, interference, fluorescence, infrared (IR), and Raman microscopy have proven to be very valuable tools, as they are capable of following chemical events at the single catalyst particle level and have been applied to the study of catalytic processes using large zeolite crystals as models. ${ }^{10-15}$ For example, the coke formation in zeolite catalysts ZSM-5 or SAPO-34 in a MTO process was followed by in situ UV-vis microspectroscopy and

(5) Chheda, J. N.; Huber, G. W.; Dumesic, J. A. Angew. Chem., Int. Ed. 2007, 46, 7164-7183.

(6) (a) Bjørgen, M.; Bonino, F.; Kolboe, S.; Lillerud, K.-L.; Zechina, A.; Bordiga, S. J. Am. Chem. Soc. 2003, 125, 15863-15868. (b) Weckhuysen, B. M.; Rosynek, M. P.; Lunsford, J. H. Catal. Lett. 1998, 52, 31-36. (c) Guisnet, M.; Magnoux, P. Appl. Catal., A 2001, 212, 8396. (d) Pazé, C.; Sazaka, B.; Zecchina, A.; Dwyer, J. D. J. Phvs. Chem. $B$ 1999, 103, 9978-9986. (e) Lange, J. P.; Gutsze, A.; Karge, H. G. J. Catal. 1988, 114, 136-143. (f) Karge, H. G.; Lange, J. P.; Gutsze, A.; Laniecki, M. J. Catal. 1988, 114, 144-152. (g) Lange, J. P.; Gutsze, A.; Allgeier, J.; Karge, H. G. Appl. Catal. 1988, 45, 345-356.

(7) (a) Van Donk, S.; Bus, E.; Broersma, A.; Bitter, J. H.; de Jong, K. P. Appl. Catal., A 2002, 237, 149-159. (b) Chen, D.; Rebo, H. P.; Moljord, K.; Holmen, A. Chem. Eng. Sci. 1996, 51, 2687-2692.

(8) (a) Bleken, F.; Bjørgen, M.; Palumbo, L.; Bordiga, S.; Svelle, S.; Lillerud, K. P.; Olsbye, U. Top. Catal. 2009, 52, 218-228. (b) Bjørgen, M.; Svelle, S.; Joensen, F.; Nerlov, J.; Kolboe, S.; Bonino, F.; Palumbo, L.; Bordiga, S.; Olsbye, U. J. Catal. 2007, 249, 195-207.

(9) (a) Cerqueira, H. S.; Sievers, C.; Joly, G.; Magnoux, P.; Lercher, J. A. Ind. Eng. Chem. Res. 2005, 44, 2069-2072. (b) Bauer, F.; Chen, W. H.; Bilz, E.; Freyer, A.; Sauerland, V.; Liu, S. B. J. Catal. 2007, 251, $258-270$.

(10) Mores, D.; Stavitski, E.; Kox, M. H. F.; Kornatowski, J.; Olsbye, U.; Weckhuysen, B. M. Chem.-Eur. J. 2008, 14, 11320-11327.

(11) (a) Karwacki, L.; et al. Nat. Mater. 2009, 8, 959-965. (b) Karwacki, L.; Stavitski, E.; Kox, M. H. F.; Kornatowski, J.; Weckhuysen, B. M. Angew. Chem. Int. Ed. 2007, 46, 7228-7231. (c) Kox, M. H. F.; Stavitski, E.; Weckhuysen, B. M. Angew. Chem.. Int. Ed. 2007, 20 3652-3655. (d) Stavitski, E.; Kox, M. H. F.; Weckhuysen, B. M. Chem.-Eur. J. 2007, 13, 7057-7065. (e) Kox, M. H. F.; Stavitski, E.; Groen, J. C.; Perez-Ramirez, J.; Kapteijn, F.; Weckhuysen, B. M. Chem.-Eur. J. 2008, 14, 1718-1725. (f) Kox, M. H. F.; Mijovilovich, A.; Sattler, J. J. H. B.; Stavitski, E.; Weckhuysen, B. M. ChemCatChem 2010, 2, 564-571.

(12) Weckhuysen, B. M. Angew. Chem. Int. Ed. 2009, 48, 4910-4943.

(13) (a) Stavitski, E.; Kox, M. H. F.; Swart, I.; de Groot, F. M. F.; Weckhuysen, B. M. Angew. Chem. Int. Ed. 2008, 47, 3543-3547. (b) Kox, M. H. F.; Domke, K. F.; Day, J. P. R.; Rago, G.; Stavitski, E.; Bonn, M.; Weckhuysen, B. M. Angew. Chem., Int. Ed. 2009, 48, $8990-8994$. confocal fluorescence microscopy. ${ }^{10}$ It was thus possible to visualize the evolution of carbonaceous species responsible for catalyst deactivation in a time- and space-resolved manner over a zeolite crystal. ${ }^{10}$ Besides such gas-phase reactions, these techniques have also provided information on single catalytic events in a time- and space-resolved manner for the reactions taking place in liquid phase. ${ }^{13,11}$ In addition, IR microscopy and Coherent Anti-Stokes Raman Scattering (CARS) microscopy recently provided interesting details on the distribution and diffusion of reactant species in an individual zeolite crystal. ${ }^{11 d, 13 a, 15}$

In a recent study, we have shown that $\mathrm{H}$-Beta zeolite is an active and selective catalyst for the etherification of biomassbased alcohols, particularly glycols, with long linear alkenes under solvent-free conditions. ${ }^{16}$ For example, the solid-acidcatalyzed etherification of 1,2-propylene glycol (1,2PG) with 1 -octene yielded the mono- (C8) and the di-ether (C16) with more than $90 \%$ selectivity (Scheme 1). Although selectivity to the desired products was high for all substrates studied, a rather large influence of the polyol substrate on conversion was observed. For glycols and alcohols, for instance, conversions over $50 \%$ were readily obtained; however, for glycerol a maximum conversion of only $20 \%$ could be obtained with H-Beta zeolites even under optimized reaction conditions. Catalyst deactivation turned out to be more severe for glycerol than for the other substrates. In addition, the use of different alkenes resulted in significant differences in both conversion as well as selectivity. Closer inspection of the obtained results pointed at a large influence of the hydrophilicity/hydrophobicity of the substrate on the outcome of the reaction, typical for liquidphase reactions that involve both a polar and an apolar phase.

To allow for a systematic evaluation of these parameters on etherification activity, selectivity, and catalyst deactivation, we decided to perform a spectroscopic analysis of the zeolite (at both the bulk and the single catalyst particle level) in order to asses the reactivity and propensity toward coke formation of the reactants (i.e., alcohol or alkene), both independently as well as with real reaction mixtures under realistic conditions. This paper therefore aims at investigating the catalytic activity of H-Beta zeolites as solid acid catalysts in liquid-phase reaction that involves several reaction pathways, one of these causing the deactivation of the catalyst by coke production. To this extent the direct etherification of alcohols with long linear alkenes ${ }^{16}$ under solvent-free conditions has been studied by confocal fluorescence microscopy to allow visualization of coke deposition on a single H-Beta zeolite crystal in a space-resolved manner. The data obtained from the single particles was combined with the results obtained with bulk techniques, such as FT-IR, TG-DTA, and UV-vis spectroscopy, which enabled us to understand the etherification processes that take place at the individual zeolite crystal particle and to localize the formation as well as the source of the deactivating species. The 
conclusions gained from the studies on the large model H-Beta zeolite crystals were further confirmed by catalytic results obtained with different H-Beta zeolites having different particle size and physicochemical properties.

\section{Materials and Methods}

Chemicals and Catalyst Materials. The following chemicals were used: glycerol ( $>99 \%$, Acros), 1,2-propylene glycol ( $>99 \%$, Acros), 1-octene (99+\%, Acros), 1,3-propylene glycol ( $>99 \%$, Fluka), and ethylene glycol ( $>99 \%$, Fluka). Zeolite $\mathrm{NH}_{4}{ }^{+}$-Beta (Si/ $\mathrm{Al}=12.5) \mathrm{CP} 814 \mathrm{E}$ was obtained from Zeolyst, and H-Beta (40.5) was provided by ExxonMobil. The zeolites that were in the $\mathrm{NH}_{4}{ }^{+}$ form were calcined before reaction and transformed into the $\mathrm{H}^{+}$ form. The following calcination procedure was used: heating from 25 to $500{ }^{\circ} \mathrm{C}$ at a rate of $1{ }^{\circ} \mathrm{C} / \mathrm{min}$ and keeping the temperature at $500{ }^{\circ} \mathrm{C}$ for $6 \mathrm{~h}$. Hereafter, zeolites will be denoted as, e.g., Beta (12.5) instead of $\mathrm{H}-\mathrm{Beta}(\mathrm{Si} / \mathrm{Al}=12.5)$.

Large zeolite Beta crystallites were synthesized according to the method of Sano et al. ${ }^{17}$ For synthesis of Beta (45), $2.40 \mathrm{~g}$ of silica (Sipernat 50, Evonik Degussa), $0.078 \mathrm{~g}$ of $\mathrm{Al}(\mathrm{OH})_{3}(0.079)(>63.5 \%$ $\mathrm{Al}_{2} \mathrm{O}_{3}$, Acros), and $0.592 \mathrm{~g}$ of $\mathrm{NH}_{4} \mathrm{~F}$ ( $>98 \%$, Sigma-Aldrich) were added into $7.57 \mathrm{~g}$ of a tetraethylammonium hydroxide solution (TEAOH, 35 wt \%, Sigma-Aldrich), which resulted in a gel with a molar composition of $1.0 \mathrm{SiO}_{2}: 0.0125 \mathrm{Al}_{2} \mathrm{O}_{3}: 0.225 \mathrm{TEAOH}: 0.4 \mathrm{NH}_{4} \mathrm{~F}$ : $7.14 \mathrm{H}_{2} \mathrm{O}$. The mixture was stirred at room temperature for $1 \mathrm{~h}$ and then transferred into a Teflon-lined steel autoclave with a full capacity volume of $50 \mathrm{~mL}$ (inner diameter of the Teflon bottle of $34 \mathrm{~mm}$ and height of $55 \mathrm{~mm}$ ). The autoclave was placed in a preheated oven at $170{ }^{\circ} \mathrm{C}$ for 7 days and afterward quenched with tap water. The precipitated product was washed with three batches of hot water $\left(70-80^{\circ} \mathrm{C}\right)$. The microcrystalline product was obtained by filtration, dried at $60{ }^{\circ} \mathrm{C}$ overnight and calcined before testing. The partially calcined H-Beta (45) zeolite was obtained by heating the as-synthesized Beta (45) zeolite to $400{ }^{\circ} \mathrm{C}$ with a rate of $1{ }^{\circ} \mathrm{C} /$ min and keeping it there for $1 \mathrm{~h}$.

Modification through silylation of the H-Beta zeolite was carried out according to the method reported by Lercher et al. ${ }^{18}$ Two grams of H-Beta (12.5) were added to $50 \mathrm{~mL}$ of hexane solution, and the solution was heated to reflux under vigorous stirring. After $10 \mathrm{~min}$ a solution of tetraethylorthosilicate (Acros 98\%) corresponding to 4 wt $\% \mathrm{SiO}_{2}$ on the zeolite material was added. The mixture was stirred and kept under reflux for another $1.5 \mathrm{~h}$. Afterward the hexane was removed by evaporation, and the sample was dried at $120^{\circ} \mathrm{C}$

(14) (a) Roeffaers, M. B. J.; De Cremer, G.; Libeert, J.; Ameloot, R.; Dedecker, P.; Bons, A.-J.; Buckins, M.; Martens, J. A.; Sels, B. F.; De Vos, D. E.; Hofkens, J. Angew. Chem., Int. Ed. 2009, 49, 92859289. (b) Roeffaers, M. B. J.; Sels, B. F.; Uji-I, H.; De Schryver, F. C.; Jacobs, P. A.; De Vos, D. E.; Hofkens, J. Nature 2006, 439, 572-575. (c) Roeffaers, M. B. J.; Ameloot, R.; Bons, A. J.; Mortier, W.; De Cremer, G.; De Kloe, R.; Hofkens, J.; De Vos, D. E.; Sels, B. F. J.Am. Chem. Soc. 2008, 130, 13516-13517. (d) Roeffaers, M. B. J.; Sels, B. F.; Uji-i, H.; Blanpain, B.; L’hoest, P.; Jacobs, P. A.; De Schryver, F. C.; Hofkens, J.; De Vos, D. E. Angew. Chem., Int. Ed. 2007, 46, 1706-1709.

(15) (a) Lei, Z.; Chmelik, C.; van Laak, A. N. C.; Kärger, J.; de Jongh, P. E.; de Jong, K. P. Chem. Commun. 2009, 6424-6426. (b) Kärger, J.; Kortunov, P.; Vasenkov, S.; Heinke, L.; Shah, D. B.; Rakoczy, R. A.; Traa, Y.; Weitkamp, J. Angew. Chem., Int. Ed. 2006, 45, 78467849 .

(16) (a) Ruppert, A. M.; Parvulescu, A. N.; Arias, M.; Hausoul, P. J. C.; Bruijnincx, P. C. A.; Klein Gebbink, R. J. M.; Weckhuysen, B. M. J. Catal. 2009, 268, 251-259. (b) Parvulescu, A. N.; Hausoul, P. J. C.; Bruijnincx, P. C. A.; Klein Gebbink, R. J. M.; Weckhuysen, B. M. Catal. Today, doi: 10.1016/j.cattod. 2010.05.021.

(17) Lu, B.-W.; Jon, H.; Kanai, T.; Oumi, Y.; Itabashi, K.; Sano, T. $\underline{J}$ Mater. Sci. 2006, 41, 1861-1864.

(18) (a) Reitmeier, S. J.; Gobin, O. C.; Jentys, A.; Lercher, J. A. Angew. Chem. Int. Ed. 2009, 48, 533-538. (b) Zheng, S.; Heydenrych, H. R.; Jentys, A.; Lercher, J. A. J. Phys. Chem. B 2002, 106, 9552-9558. (c) Zheng, S. R.; Tanaka, H.; Jentys, A.; Lercher, J. A. J.Phvs. Chem. $\underline{B}$ 2004, 108, 1337-1343. for $2 \mathrm{~h}$ and calcined to $500{ }^{\circ} \mathrm{C}$ for $4 \mathrm{~h}$. A second cycle was performed for H-Beta $(12.5)+8$ wt $\% \mathrm{SiO}_{2}$.

Catalyst Characterization. X-ray powder diffraction (XRD) was performed using a Bruker-AXS D8 Advance powder X-ray diffractometer, equipped with automatic divergence slit, Våntec-1 detector, and Co $\operatorname{K} \alpha 1,2(\lambda=1.79026 \AA)$ source.

The specific surface areas and pore volumes were determined by $\mathrm{N}_{2}$ sorption measurements using a Micromeritics ASAP 2400 instrument. Surface areas were calculated using the BET model. The external surface area and the micropore volume were calculated by application of the $t$-plot method.

Scanning electron microscopy (SEM) measurements were performed using a FEI XL30 FEG electron microscope equipped with an EDX detector.

X-ray photoelectron spectroscopy (XPS) experiments were performed using a Specs $\mathrm{GmbH}$ setup. The excitation was done using a conventional dual anode X-ray source (Specs XR 50) using the $\mathrm{Mg} \mathrm{K} \alpha$ line $(1253.6 \mathrm{eV})$. The sample consisted of a powder dispersed on two-sided adhesive tape. In order to compensate for charging, a flood gun (Specs FG 20) was employed, operating at 3 $\mathrm{V}$ and $0.3 \mathrm{~mA}$. Photoelectrons were analyzed by using a (Specs) Phoibos 150 hemispherical analyzer, with estimated resolution (fwhm) of 0.85 at $12 \mathrm{eV}$ pass energy on Al2p and Si2p core levels excited with $\mathrm{Mg} \mathrm{K} \alpha$. For the actual experiments, a pass energy of $30 \mathrm{eV}$ (estimated resolution $1.3 \mathrm{eV}$ fwhm) was employed for the core levels and $50 \mathrm{eV}$ for survey scans.

Samples of H-Beta (45) were taken from the reaction mixture at different reaction times, washed several times with organic solvents (ethanol and dichloromethane), and separated by centrifugation. The resulting samples were dried under nitrogen flow at room temperature for $1 \mathrm{~h}$ and used for confocal fluorescence measurements.

A Nikon Eclipse LV150 upright microscope with $50 \times 0.55 \mathrm{NA}$ dry objective was used for fluorescence studies. Fluorescence microphotographs were collected using 510-560 nm excitation light from the mercury source. Confocal images were acquired with a Nikon D-Eclipse C1 head connected to the laser light sources (488 and $561 \mathrm{~nm}$ ). The emission was detected with two photomultiplier tubes in the ranges 510-550 and 575-635 nm, respectively, in order to avoid channel overlap.

TG-DTA measurements of the spent catalysts were performed with a Shimadzu DTG-60 instrument, and the sample was heated from room temperature to $600{ }^{\circ} \mathrm{C}$ at a rate of $10{ }^{\circ} \mathrm{C} / \mathrm{min}$ under air using $\mathrm{Al}_{2} \mathrm{O}_{3}$ as reference.

The FT-IR measurements were performed on a Perkin-Elmer 2000 FTIR spectrometer with a data point resolution of $4 \mathrm{~cm}^{-1}$ with a DTGS detector with an accumulation of 16 scans per spectrum. The samples were diluted prior measurements with $\mathrm{KBr}$ in a 5:95 mixture ratio. Diffuse reflectance (DR) UV-vis measurements were done on a Cary $500 \mathrm{UV}-$ vis-NIR instrument in the region $250-800 \mathrm{~nm}$. The samples were diluted with $\mathrm{MgO}$ in a 20: 80 mixture ratio.

Catalysts Testing. The reactions conditions were chosen based on previous optimization studies. ${ }^{16}$ In a typical etherification reaction $0.05 \mathrm{~mol}$ of alcohol, $0.15 \mathrm{~mol}$ of 1-octene, and $0.5 \mathrm{~g}$ of catalyst were loaded in a $40 \mathrm{~mL}$ stainless steel Parr autoclave. The autoclave was flushed with Ar three times and then pressurized with an additional 10 bar of Ar. The autoclave was heated to 140 ${ }^{\circ} \mathrm{C}$ under continuous mechanical stirring (750 rpm). The starting point of the reaction was taken when the autoclave reached the reaction temperature. When the reaction was considered finished, the autoclave was cooled to $40{ }^{\circ} \mathrm{C}$, and the reaction mixture was dissolved in a known amount of ethanol. The catalyst was separated by filtration, and a sample of the solution was taken for further analysis. The conversions were calculated from the gas chromatographic analysis using a Shimadzu 2010 system with a CP-WAX 57CB column $(25 \mathrm{~m} \times 0.2 \mathrm{~mm} \times 0.2 \mu \mathrm{m})$. Products were identified 
Scheme 2. Source of Coke Formation during the Etherification of Biomass-Based Alcohols with Long Linear Alkenes

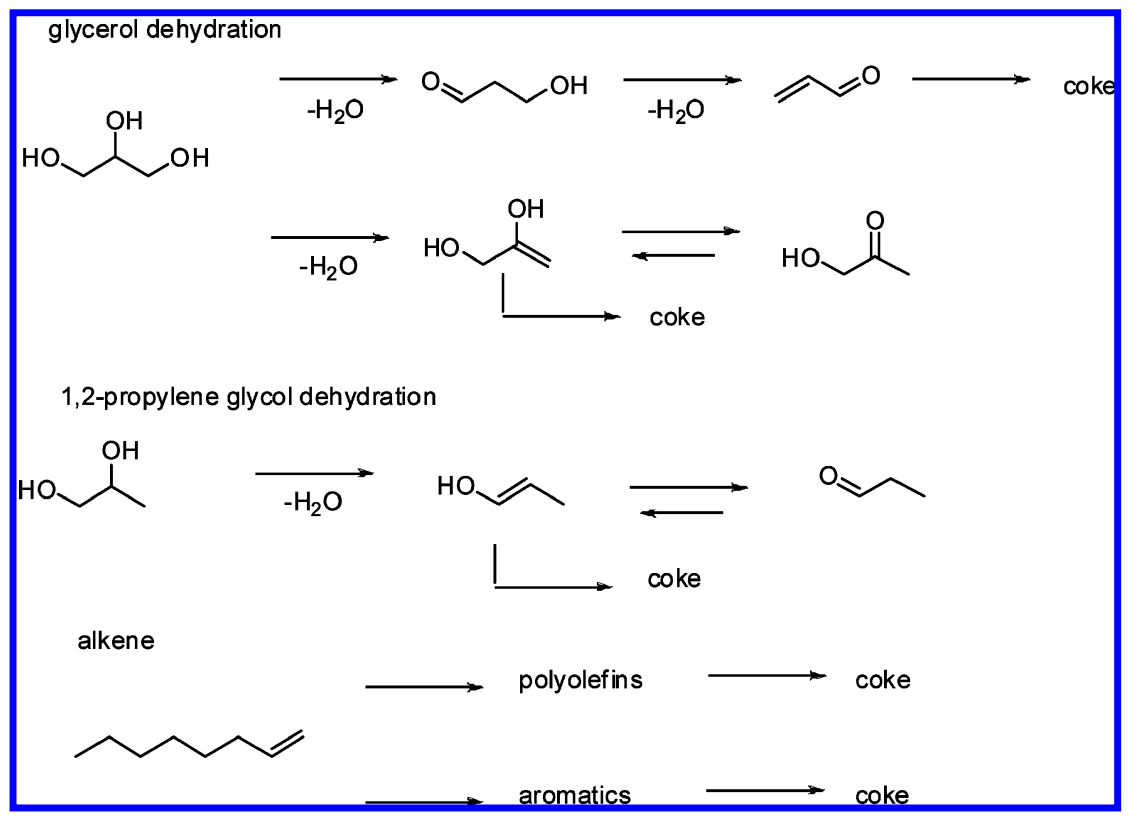

with a GC-MS from Shimadzu with a CP-WAX 57CB column $(30 \mathrm{~m} \times 0.2 \mathrm{~mm} \times 0.2 \mu \mathrm{m})$.

\section{Results and Discussion}

Spectroscopic Measurements on Micrometer-Size H-Beta crystals. Large crystalline particles are often used as models for studying zeolite activity since features due to inhomogeneities in their structure and/or catalytic activity are often larger than the diffraction limit, making them amenable to fluorescence, interference, UV-vis, CARS, or IR microscopic measurements ${ }^{10-15}$ On the basis of these results a relation can be established between the catalytic activity and zeolite properties that can be in principle extended to zeolites having smaller particle sizes. Therefore, we decided to study our etherification reaction of polyols, such as glycerol and various glycols, with long linear alkenes over an H-Beta zeolite with large single crystal particles of $9 \mu \mathrm{m}$ size as model catalyst under solvent-free conditions.

A change in color was observed for the recovered zeolite catalysts after catalytic reaction. These color changes can be attributed to the formation of carbonaceous deposits. As a matter of fact, both the polyol and alkene can lead to the formation of coke species, according to Scheme 2. As already mentioned, alkene side reactions are known to lead toward products of higher molecular weight, which are difficult to remove from the solid acid catalysts. The alcohols can also form highly reactive alkenes under these conditions through dehydration. For example, dehydration of glycerol on acid catalysts may lead to acrolein formation, ${ }^{19 \mathrm{a}, \mathrm{b}, \mathrm{e}}$ whereas reactive enol intermediates can be formed by dehydration from glycols such as 1,2-propylene. ${ }^{19 \mathrm{c}, \mathrm{d}}$ These unsaturated intermediates can themselves polymerize and produce coke. ${ }^{19,6 \mathrm{c}}$

A first set of experiments addressed the interaction of the alcohol with the H-Beta (45) zeolite in the absence of the alkene

(19) (a) Pariente, S.; Tanchoux, N.; Fajula, F. Green Chem. 2008, 11, 12561261. (b) Corma, A.; Huber, G. W.; Sauvanaud, L.; O'Connor, P. J. Catal. 2008, 257, 163-171. (c) Williams, B. S. Tetrahedron 2002, 58, 2091-2094. (d) Cheng, L.; Philip Ze, X. Catal. Lett. 2009, 130, 100-107. (e) Pagliaro, M.; Rossi, M. In The Future of Glycerol: New Uses of a Versatile Raw Material; Royal Society of Chemistry: Cambridge, 2008; Chapter 5. under the reaction conditions used for etherification (reaction temperature of $140{ }^{\circ} \mathrm{C}$ and Ar pressure). Colored zeolite crystals were taken out of the reaction mixture at different reaction times and analyzed by diffuse reflectance (DR) UV-vis and FT-IR. The results of these measurements are presented in Figure 1 (see also Figure 7 in the Supporting Information) and indicate that the change in color is due to the formation of carbonaceous species on the catalyst during reaction of the alcohol with the zeolite. For all glycols, the FT-IR spectra of the catalysts (Figure 1a) show vibrations at 2863,2930, and $2958 \mathrm{~cm}^{-1}$, which correspond to $v_{\mathrm{s}}\left[\mathrm{CH}_{3}\right], v_{\mathrm{as}}\left[\mathrm{CH}_{2}\right]$, and $v_{\mathrm{as}}\left[\mathrm{CH}_{3}\right]$ vibrations, respectively. ${ }^{1,19 \mathrm{c}}$ Important to mention is that no bands above $3000 \mathrm{~cm}^{-1}$ corresponding to aromatic $[\mathrm{CH}]$ bonds were observed. The band at $1634 \mathrm{~cm}^{-1}$, a region where coke bands are generally observed, was attributed to water adsorbed on the zeolite, and the band at $1460 \mathrm{~cm}^{-1}$ to $\left[\mathrm{CH}_{3}\right]$ asymmetrical bending. For glycerol, two additional strong bands appeared at 1714 and $1749 \mathrm{~cm}^{-1}$, which may be attributed to adsorbed oxygenated species, such as aldehydes. ${ }^{19 c}$ The DR UV-vis measurements aid in further understanding the nature of these coke species (Figure 1b). For 1,2-propylene glycol treated zeolite two bands with absorption maxima at 370 and $457 \mathrm{~nm}$ can be observed (Figure 1b, b). The band at $370 \mathrm{~nm}$ has been previously associated with the presence of polyenilic cations ${ }^{1}$ and therefore with the presence of a soft coke of the polyolefinic type. On the other hand, the band at $457 \mathrm{~nm}$ could be attributed to unsaturated species with a higher degree of conjugation. For zeolite samples removed from the glycerol reaction mixture a broad band with maxima at $460 \mathrm{~nm}$ was obtained, which also may indicate a higher degree of conjugation ${ }^{6 a}$ in the coke species which correlates with the more pronounced coloration of the catalyst. Although very useful for obtaining some insight into the nature of the coke that is formed due to side reactions of the polyols, the UV-vis and FT-IR measurements were unable to provide information at the individual particle level or further differentiate between the catalytic results obtained with different glycols.

In recent studies we reported that the coke generated in the course of the template decomposition in the molecular sieves 

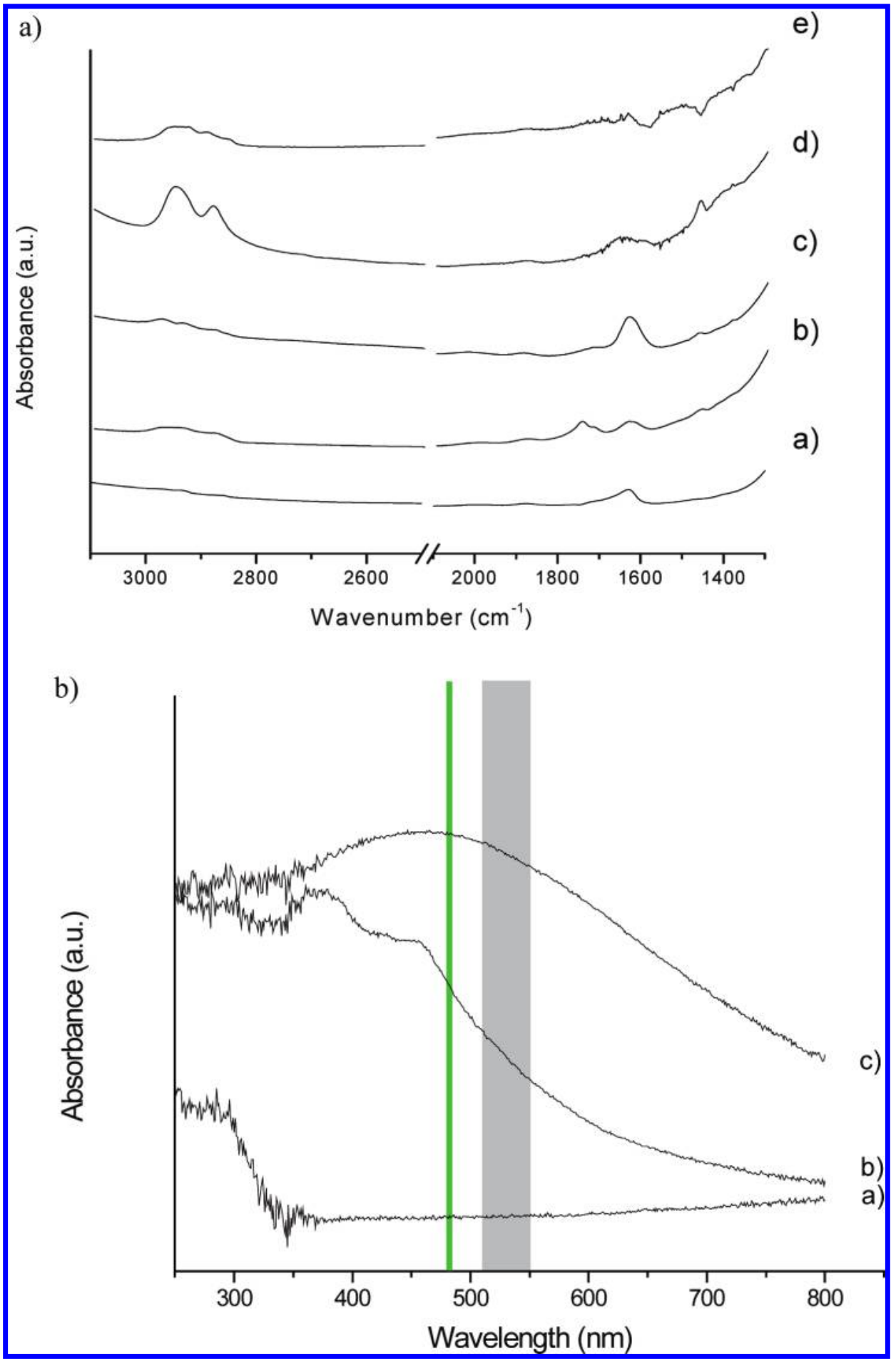

Figure 1. (a) FT-IR spectra of the H-Beta (45) zeolite: a) blank zeolite; samples taken after $3 \mathrm{~h}$ of reaction at $140{ }^{\circ} \mathrm{C}$ with b) glycerol, c) 1,2 -propylene glycol, d) ethylene glycol, and e) 1,3-propylene glycol. (b) DR UV-vis spectra of the H-Beta (45) zeolite: a) blank zeolite; samples taken after 3 h of reaction at $140{ }^{\circ} \mathrm{C}$ with b) 1,2-propylene glycol and c) glycerol. Green bar indicates the laser excitation wavelength at $488 \mathrm{~nm}$, and the gray area is the detection region at $510-550 \mathrm{~nm}$.

possesses fluorescent properties. ${ }^{1 \mathrm{a}, \mathrm{b}}$ making it possible to determine its spatial distribution within the catalyst particle using confocal fluorescence microscopy. The zeolite crystals exhibit only weak fluorescence in the absence of any organic compound. Therefore, monitoring the formation of coke products and mapping their distribution in the etherification reaction may help us understand the nature of the reactant's interaction with the active sites of the zeolite and the distribution of these catalytic active sites at the level of an individual catalytic grain.
The interaction of the polyol with the zeolite can be deducted from the spatial distribution of the alcohol-derived coke species in the zeolite crystal. The spatial distribution of these coke products will indicate the spatial distribution of the active sites that interact with the alcohol. Samples of the zeolite material were taken at different reaction times and analyzed with confocal fluorescence microscopy. The confocal fluorescence measurements (see Supporting Information, video 1 and 2) offered a 3-D image of an individual zeolite crystal and the distribution 


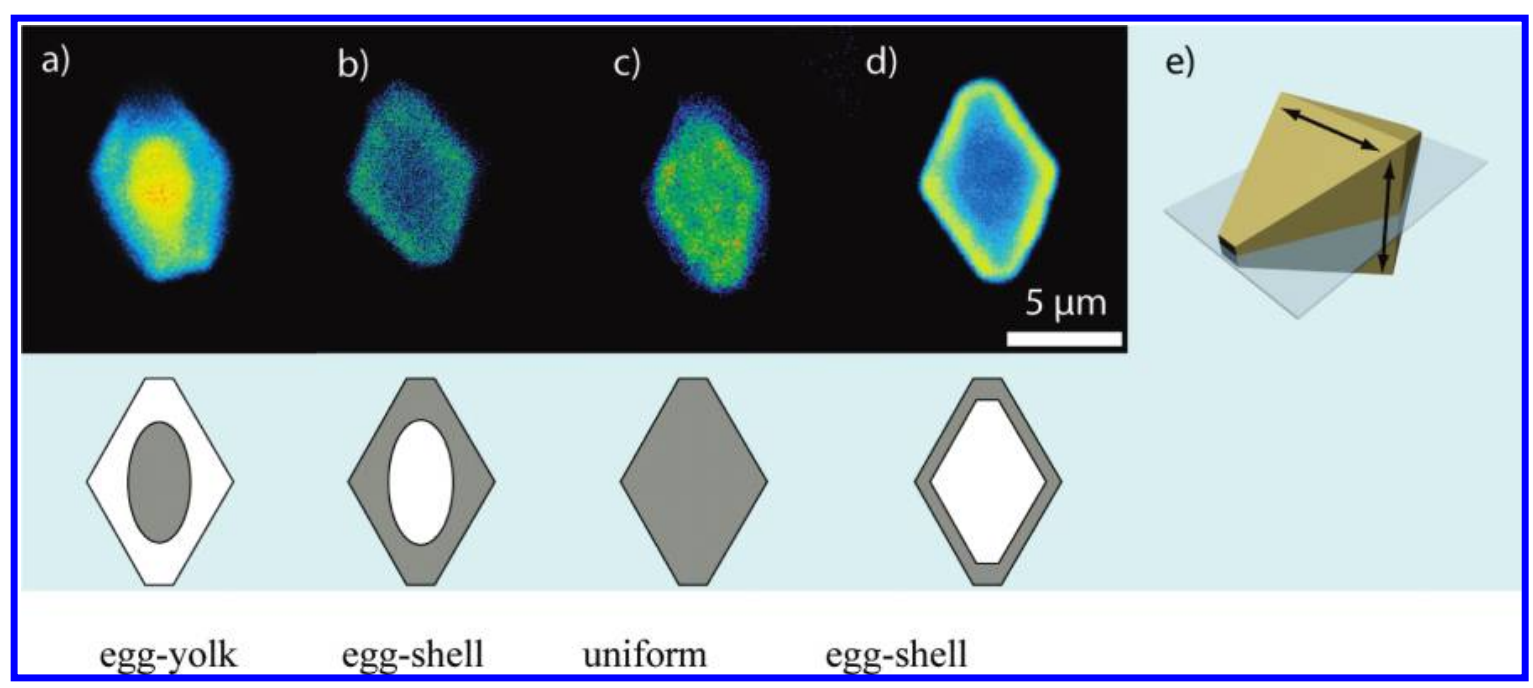

Figure 2. Fluorescence intensity maps of an individual H-Beta (45) zeolite crystal recorded with a laser excitation of $488 \mathrm{~nm}$ (detection at $510-550 \mathrm{~nm}$ ). Samples were taken after $3 \mathrm{~h}$ of reaction at $140{ }^{\circ} \mathrm{C}$ with (a) glycerol, (b) ethylene glycol, (c) 1,3-propylene glycol, and (d) 1,2-propylene glycol. (e) Schematic representation of the slice at which the confocal fluorescence measurements have been performed, with the arrows indicating the direction of the pores.

of the fluorescent species formed in the reaction. In Figure 2 2-D confocal fluorescence intensity maps of the truncated bipyramidal H-Beta zeolite crystal after reaction are presented as measured from the middle plane of the crystal. A $488 \mathrm{~nm}$ wavelength was chosen on the basis of the UV-vis measurements to ensure excitation in the absorption band of the coke species formed (Figure 1b). The fluorescence intensity increased with reaction time, indicating an increase in the amount of coke species formed. A relation between the type of the polyol and the distribution of fluorescent species inside the zeolite crystal was observed. It is important to note that these species are strongly attached to the zeolite crystal, as the vigorous washing performed before the fluorescence measurements did not remove them. In the case of glycerol, the most polar of the alcohols studied, it can be seen that the fluorescent coke species are concentrated in the center of the zeolite crystal (Figure 2a) and higher fluorescence intensity is obtained compared to other glycols. For these glycols the distribution of the fluorescent species appears to be different. In the case of ethylene glycol (EG) less fluorescence is observed, the coke products being more concentrated on the external surface of the crystal (Figure 2b). A similar but much more pronounced concentration profile of fluorescent species is observed for 1,2-propylene glycol (1,2PG) where the fluorescent "coke" species are predominantly detected on the external surface of the zeolite and almost no fluorescene is observed in the center of the crystal (Figure 2d). In the case of the isomeric 1,3-propylene glycol (1,3-PG), on the other hand, the fluorescent species are almost uniformly distributed over the zeolite crystal (Figure 2c).

The spatial coke distribution profiles obtained over the catalyst crystals can be schematically depicted as shown in Figure 2 and, interestingly, resemble the profile distributions of metal ion species during solid support impregnation processes, generally known as egg-yolk, egg-shell, and uniform distributions. ${ }^{20}$ Following this analogy, coke formation for glycerol resembles an egg-yolk distribution (Figure 2a), whereas EG and 1,2PG produce an egg-shell distribution (Figure $2 b$ and d). Most importantly, this distribution indicates a different adsorption of the alcohol in the zeolite crystal. The more hydrophilic alcohol, i.e., glycerol, seems able to penetrate the interior of the zeolite and be transformed there to coke-like products, whereas less hydrophilic glycols such as EG and 1,2PG remain more concentrated on the external surface. On the basis of XPS measurements (see Figure 1 of Supporting Information), we know that the H-Beta (45) zeolite crystal has a higher $\mathrm{Al}$ concentration on its external surface ( $\mathrm{Si} / \mathrm{Al}$ of 12 ) as compared to the bulk composition ( $\mathrm{Si} / \mathrm{Al}$ of 45 ). Therefore, the external surface is more hydrophilic and also in principle contains a higher number of Brønsted acid sites. Under these conditions, the hydrophilic properties of the catalyst nicely correlate with the ones of the alcohol and explain the observed trend in the activity.

In a second set of experiments the alkene interaction with the H-Beta (45) zeolite was investigated. Similar reaction conditions were used for studying the effect of the alkene on deactivation. Linear C6 to $\mathrm{C} 12 \alpha$-olefins were used in the study in order to establish the effect of the chain length on zeolite deactivation and etherification activity. In addition to the fluorescence microscopy study, the zeolite samples recovered from the reaction were also analyzed by FT-IR and DR UV-vis. The FT-IR spectra of the large crystal zeolite samples are presented in Figure 3a. Some differences in the position and the intensity ratio of the bands in the $2900 \mathrm{~cm}^{-1}$ region were observed as a function of the alkene chain length. For the sample treated with 1-hexene (Figure 3a, b) the band at $2965 \mathrm{~cm}^{-1}$ attributed to a $v_{\text {as }}\left[\mathrm{CH}_{3}\right]$ vibration is more intense than the bands at $2930 \mathrm{~cm}^{-1}$ of $v_{\text {as }}\left[\mathrm{CH}_{2}\right]$ observed for the 1-octene and 1-dodecene treated samples (Figure $3 \mathrm{a}, \mathrm{c}$ and d). For the latter two samples, the band at $2930 \mathrm{~cm}^{-1}$ of $v_{\text {as }}\left[\mathrm{CH}_{2}\right]$ is more intense than the band at $v_{\text {as }}\left[\mathrm{CH}_{3}\right]$ which is in accordance with the longer alkyl chain. Furthermore, a new band evolves at $2859 \mathrm{~cm}^{-1}$ that is not observed for the 1-hexene sample and may be due to an asymmetric $\left[\mathrm{CH}_{3}\right]$ group vibration. ${ }^{6 a}$ Other bands attributed

(20) (a) Bergwerff, J. A.; Lysova, A. A.; Espinosa-Alonso, L.; Koptyug, I. V.; Weckhuysen, B. M. Chem.-Eur. J. 2008, 14, 2363-2374. (b) Espinosa-Alonso, L.; Lysova, A. A.; De Peinder, P.; de Jong, K. P.; Koptyug, I. V.; Weckhuysen, B. M. J. Am. Chem. Soc. 2009, 131, 6525-6534. (c) Espinosa-Alonso, L.; O’Brien, M. G.; Jacques, S. D. M.; Beale, A. M.; de Jong, K. P.; Barnes, P.; Weckhuysen, B. M. J. Am. Chem. Soc. 2009, 46, 16932-16938. (d) Beale, A. M.; Jacques, S. D. M.; Bergwerff, J. A.; Barnes, P.; Weckhuysen, B. M. Angew. Chem., Int. Ed. 2007, 46, 8832-8835. (e) Bergwerff, J. A.; Lysova, A. A.; Espinosa-Alonso, L.; Koptyug, I. V.; Weckhuysen, B. M. Angew. Chem., Int. Ed. 2007, 46, 7224-7227. (f) Lysova, A. A.; Koptyug, I. V.; Sadeev, R. Z.; Parmon, V. N.; Bergwerff, J. A.; Weckhuysen, B. M. J. Am. Chem. Soc. 2005, 127, 11916-11917. 


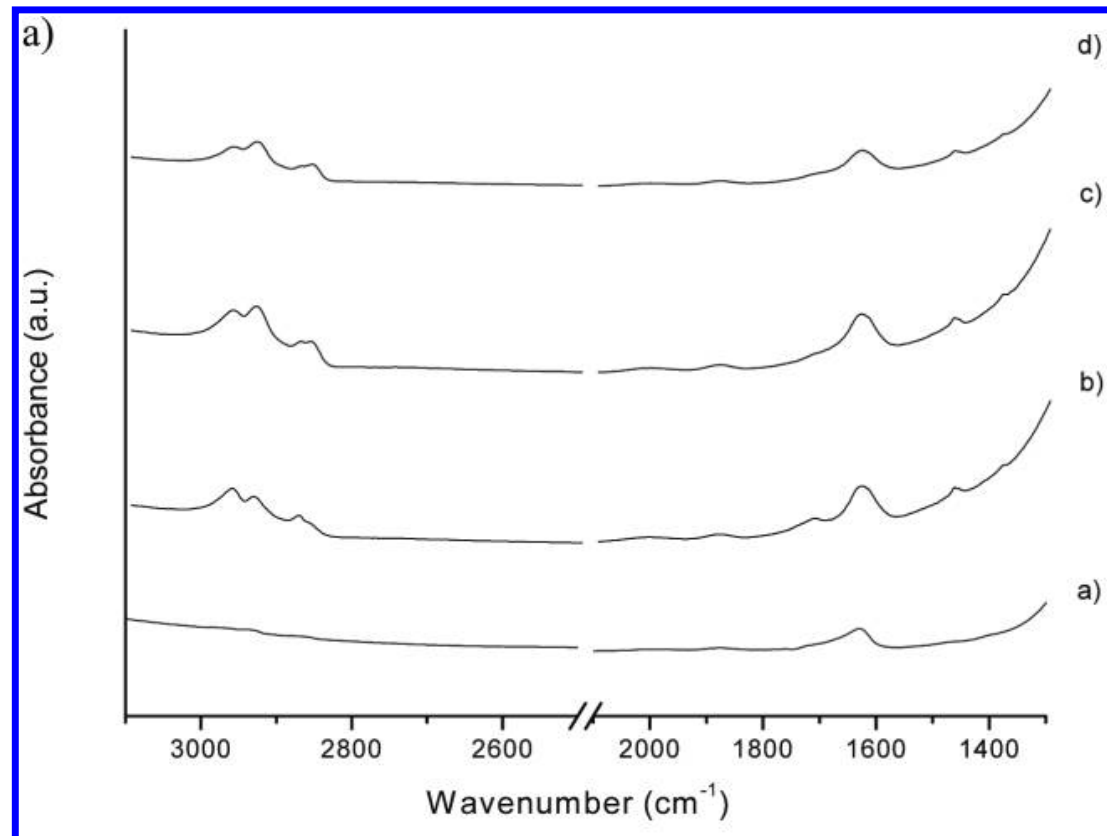

d)

c)

b)

a)

b)

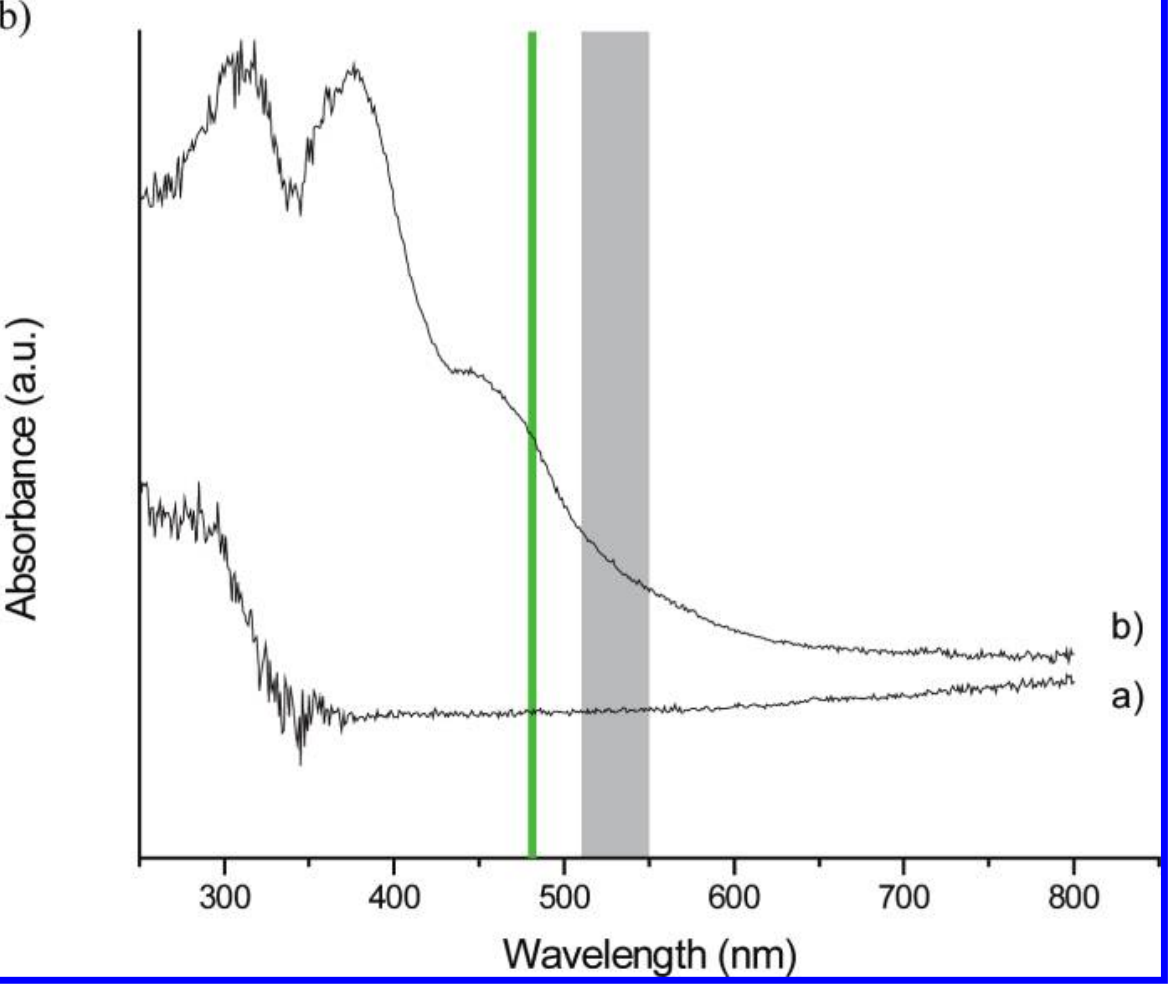

Figure 3. (a) FT-IR spectra of the H-Beta (45) zeolite: a) blank zeolite; samples taken after $3 \mathrm{~h}$ of reaction at $140{ }^{\circ} \mathrm{C}$ with b) 1 -hexene, c) 1 -octene, and d) 1-dodecene. (b) DR UV-vis spectra of the H-Beta (45) zeolite: a) blank zeolite and b) sample taken after 3 h of reaction at $140{ }^{\circ} \mathrm{C}$ with 1 -octene. Green bar indicates the laser excitation wavelength at $488 \mathrm{~nm}$, and the gray area is the detection region at $510-550 \mathrm{~nm}$.

to the presence of adsorbed alkyl species appear at 1460 and $1370 \mathrm{~cm}^{-1}$. The band at $1640 \mathrm{~cm}^{-1}$ associated with adsorbed water is also present. As in the previously discussed examples of the interaction of the alcohol with the zeolite, the DR-UV-vis measurements shed more light on the type of coke formed. The DR UV-vis spectra of the 1-octene treated zeolite shown in Figure $2 b$ give an indication on the type of species that are formed from the reaction of the alkene with the zeolite catalyst. Three bands are observed at 307, 374, and $460 \mathrm{~nm}$ that are associated with soft coke formation of the polyolefinic type. ${ }^{1,6 a}$
Confocal fluorescence measurements of the zeolite crystals now allow further mapping of the interaction of the alkenes with the acid catalyst. The results are shown in Figure 4. Also for the alkene substrates, significant differences in coke distribution were observed in the fluorescence images. For 1-octene, 1 -decene, and 1-dodecene the fluorescence is more pronounced on the external surface of the zeolite (Figure $4 b-d$ and Supporting Information videos 3 and 4), leading to an egg-shell distribution. Because of both the hydrophobic properties and possible steric constrains, the $\mathrm{C} 8$ to $\mathrm{C} 12$ alkenes are more concentrated close to or on the external surface of the zeolite 


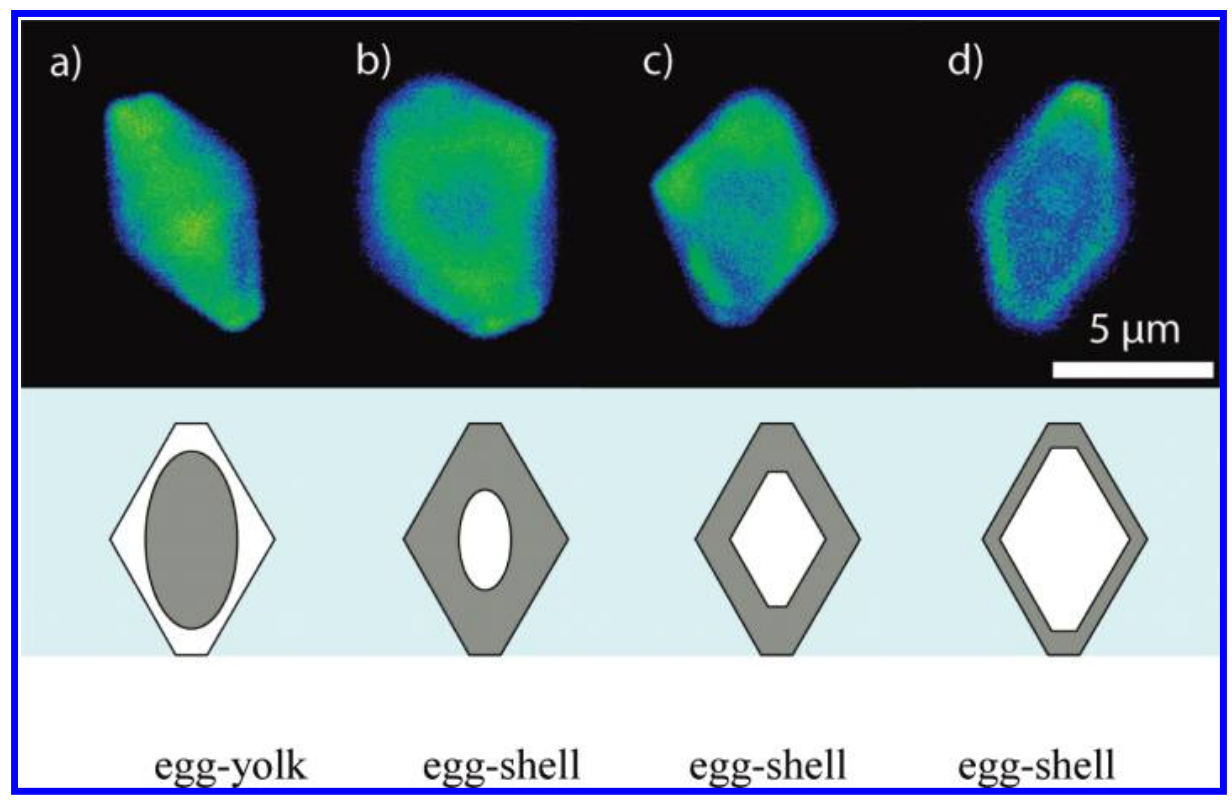

Figure 4. Fluorescence intensity maps of an individual H-Beta (45) zeolite crystal recorded with a laser excitation of $488 \mathrm{~nm}$ (detection at $510-550 \mathrm{~nm}$ ). Samples were taken after $3 \mathrm{~h}$ of reaction at $140{ }^{\circ} \mathrm{C}$ with a) 1-hexene, b) 1-octene, c) 1-decene, and d) 1-dodecene. The confocal fluorescence images were taken from the middle plane of the zeolite crystal (Figure 1e).

crystal. There they may undergo oligomerization or other reactions that lead to coke products. The alkene can slowly diffuse in the large pores of the H-Beta zeolite ${ }^{21,22}$ and block the pores of the zeolite. This explains why fluorescence is observed in the zeolite crystal but mostly close to the external surface, especially, for 1-octene (Figure 4b). The observed profiles nicely show that the smaller the alkene gets, the further it can diffuse into the zeolite, resulting in shells of increasing thickness from $\mathrm{C} 8$ to $\mathrm{C} 12$ (Figure $4 \mathrm{~b}-\mathrm{d}$ ). This is further exemplified by 1-hexene, a smaller and more hydrophilic alkene, which apparently readily enters into to the pores of the H-Beta zeolite. As can be seen from Figure 4a the fluorescence in this case is more concentrated in the center of the H-Beta zeolite.

With this information in mind we investigated the etherification process on individual H-Beta (45) zeolites by confocal fluorescence microscopy. Considering the observations made above on the individual interactions of the alcohols or alkenes with the zeolite, it was expected that we would be able to distinguish between the effects of the two reactants during the etherification process. The results are given in Figure 5 for the etherification of glycerol with 1-octene (see also video 5 in Supporting Information). When the deactivation process in the etherification of glycerol with 1-octene is followed in time, it can be observed that fluorescent species are already present after only $30 \mathrm{~min}$ of reaction both in the center and on the edges of the zeolite crystal in an egg-yolk-shell type of distribution. Based on the results obtained for the glycerol interaction with the H-Beta (45) zeolite crystal, the fluorescence in the center of the zeolite is most probably caused by a glycerol-derived byproduct. It can be clearly seen that the fluorescence intensity is increasing with the reaction time (Figure 5). The fluorescence intensity grows following the edge of the truncated bypiramid of the H-Beta zeolite (Figure 2e). On the basis of the crystal

(21) Simon-Masseron, A.; Marques, J. P.; Lopez, J. M.; Ramôa Ribeiro, F.; Gener, I.; Guisnet, M. Appl. Catal A: General 2007, 316, 75-82.

(22) (a) Da, Z.; Han, Z.; Magnoux, P.; Guisnet, M. Appl. Catal. A: General 2001, 219, 45-52. (b) De Klerk, A.; Nel, R. J. J. Ind. Eng. Chem. Res. 2007, 46, 7066-7072. (c) Magnoux, P.; Rabeharitsara, A.; Cerqueira, H. S. Appl. Catal., A 2006, 304, 142-151.

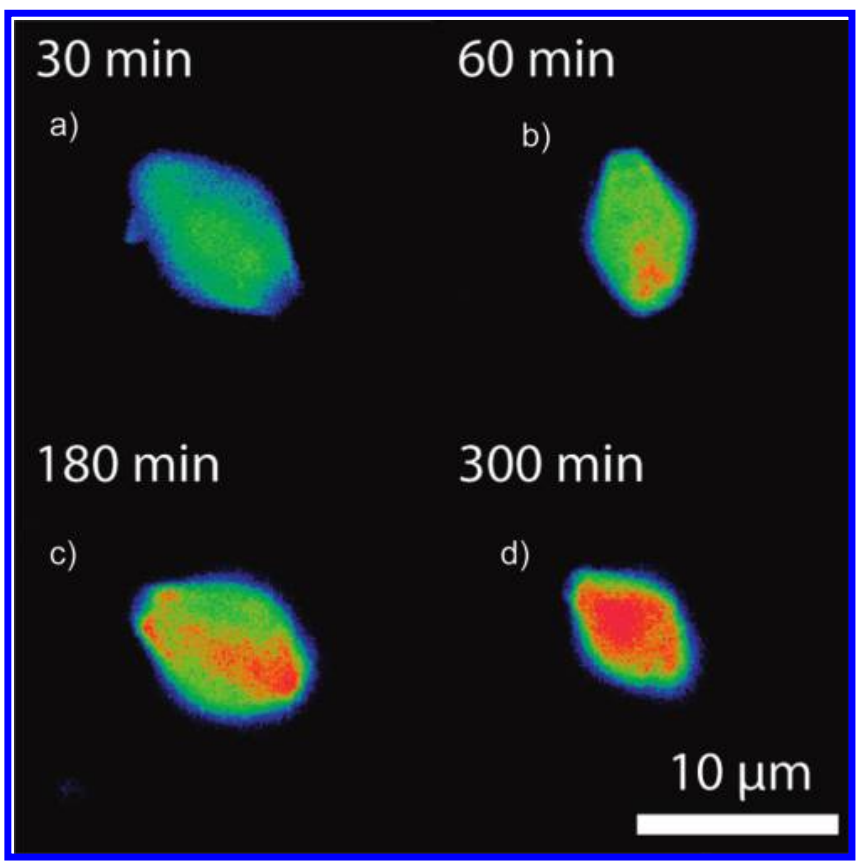

Figure 5. Fluorescence intensity maps of an individual H-Beta (45) zeolite crystal during the etherification of glycerol with 1 -octene at $140{ }^{\circ} \mathrm{C}$ as a function of time: (a) 30, (b) 60, (c) 180, and (d) $300 \mathrm{~min}$. The confocal images were recorded at $488 \mathrm{~nm}$ (detection at $510-550 \mathrm{~nm}$ ) in the middle plane of the zeolite crystal (Figure 2e).

growth of large H-Beta crystals, ${ }^{23}$ the pore structure of zeolite is perpendicular to the edge of the crystal as illustrated in Figure 2e. The growth of fluorescent species in this direction on the edge of the crystal is caused by 1 -octene. Since the alkene can easily enter into the short length pores that are present on the edge of the H-Beta crystal and block them, this process can be associated with a pore-mouth mechanism. After $5 \mathrm{~h}$ of reaction the entire zeolite crystal is covered with coke, as evidenced by

(23) Sun, J.; Zhu, G.; Chen, Y.; Li, J.; Wang, L.; Peng, Y.; Li, H.; Qiu, S. Microporous Mesoporous Mater. 2007, 102, 242-248. 


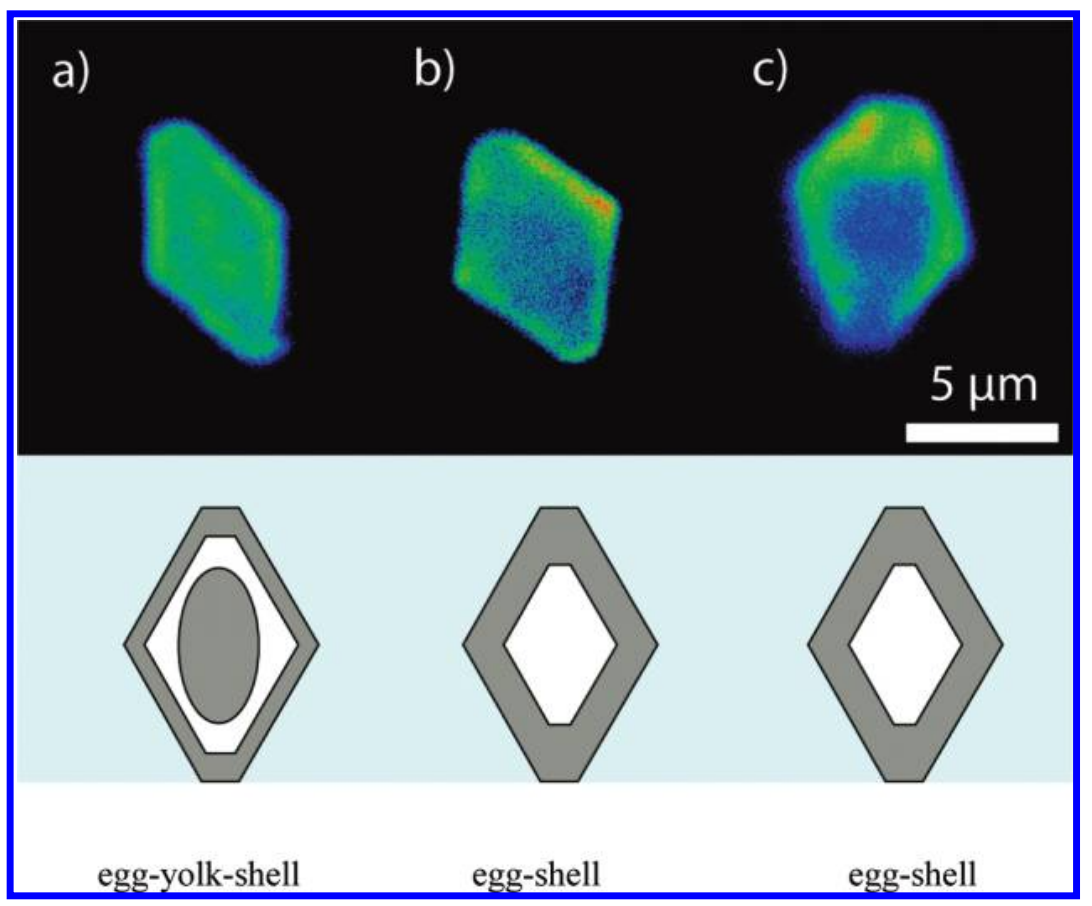

Figure 6. Fluorescence intensity maps of an individual H-Beta (45) zeolite crystal during the etherification reaction as a function of alcohol and alkene. Samples were taken after $3 \mathrm{~h}$ of reaction at $140{ }^{\circ} \mathrm{C}$ : (a) etherification of glycerol with 1-octene, (b) etherification 1,2-propylene glycol with 1-octene, and (c) etherification of 1,2-propylene glycol with 1-dodecene.

Table 1. Etherification of Glycerol and 1,2-Propylene Glycol with Powdered H-Beta Zeolites ${ }^{a}$

\begin{tabular}{|c|c|c|c|c|c|c|c|c|c|}
\hline $\mathrm{Si} / \mathrm{Al}$ (ICP) & Si/AI (XPS) & $S_{\text {Bet }}\left(\mathrm{m}^{2} / \mathrm{g}\right)$ & $S_{\text {ext }}\left(\mathrm{m}^{2} / \mathrm{g}\right)$ & alcohol & conv $(\%)$ & selc8-ether $(\%)$ & sel $_{\text {c16-ether }}(\%)$ & other $(\%)$ & particle size ${ }^{c}(\mu \mathrm{m})$ \\
\hline \multirow[t]{2}{*}{12.5} & 12 & 571 & 226 & $1,2 \mathrm{PG}$ & 76 & 82 & 6 & 9 & 0.1 \\
\hline & & & & Gly & 16 & 83 & 13 & 3 & \\
\hline 40.5 & 20 & 600 & 118 & $1,2 \mathrm{PG}^{b}$ & 71 & 83 & 8 & 9 & 0.5 \\
\hline \multirow[t]{2}{*}{45} & 12 & 275 & 41 & $1,2 \mathrm{PG}$ & 30 & 81 & 5 & 14 & 9.0 \\
\hline & & & & Gly & 2 & 70 & 15 & 15 & \\
\hline
\end{tabular}

${ }^{a}$ Etherification conditions: $0.5 \mathrm{~g}$ catalyst, $5 \mathrm{~h}, 413 \mathrm{~K}, 1$-octene/alcohol 3:1, $0.05 \mathrm{~mol}$ alcohol. ${ }^{b}$ Three hours. ${ }^{c}$ Averaged dimension over 120 particles $( \pm 5 \mathrm{~nm})$ measured by SEM.

Figure 5d. The low conversion and severe deactivation previously observed in the etherification of glycerol with 1-octene can now be explained by the rapid and extensive coke formation, as evidenced by the confocal fluorescence.

$1,2 \mathrm{PG}$ was shown to be a much better substrate for this reaction, and indeed, an entirely different fluorescence profile is observed in this case. This is illustrated in Figure 6 where $1,2 \mathrm{PG}$ interacts with the external surface of the zeolite in much the same manner as 1-octene, 1-decene, and 1-dodecene do. The distribution of fluorescent coke-like species in the etherification reaction followed the same trend, and an overall eggshell distribution was subsequently obtained. The fluorescent species were formed only on the external surface, and no fluorescence was observed in the center of the zeolite particle. Both the alcohol and the alkene thus adsorb preferentially on the external surface of the zeolite, which enhances not only ether formation but also desorption as the reactants may act as solvents as well. As a result, the microspectroscopic data shows why higher conversions are obtained for 1,2PG etherification and why the deactivation of the zeolite is reduced in this case (Figure $6 \mathrm{~b}$ and $\mathrm{c})$. The fluorescence intensity was more pronounced after the etherification of 1,2PG with 1-dodecene. Given the steric constrains of 1-dodecene compared to 1-octene, the diffusion through the pores of the H-Beta (45) zeolite crystal is much more difficult for the former substrate. If blockage occurs close to the pore mouth, the adsorption of other reactant molecules is inhibited by the long alkyl tail of the alkene. Furthermore, the preponderant polyolefinic nature of the coke was again confirmed by the FT-IR and the DR UV-vis spectra (Supporting Information Figure 7 and 9).

The confocal fluorescence microscopy results clearly indicate that the physicochemical properties of the reactants (i.e., alcohol and alkene) have a strong influence on the formation of the coke products in the zeolite crystal during the solvent-free etherification process. Under such conditions, i.e. in the absence of a solvent, the hydrophilic/hydrophobic properties of both the reactants and the zeolite catalyst strongly influence the nature and strength of the interactions between them.

From Micrometer-Scale to Nanoscale H-Beta Zeolites. To validate the conclusions of the confocal fluorescence microscopy on the model zeolite these should be correlated with catalytic results on both the model H-Beta (45) zeolites as well as on more relevant zeolite materials with smaller particle size. To this extent, two commercial H-Beta zeolites with particle sizes of 0.1 and $0.5 \mu \mathrm{m}$, together with the large $9 \mu \mathrm{m} \mathrm{H}$-Beta (45) zeolite were tested in the etherification of glycerol and 1,2PG. The results are summarized in Table 1. With 1,2-PG as the alcohol substrate, conversions over $50 \%$ were readily obtained. However, for glycerol maximum conversions of $20 \%$ were obtained with the most active H-Beta (12.5) zeolites having the smallest particle dimensions of $0.1 \mu \mathrm{m}$. This is in agreement with the confocal fluorescence microscopy results, nicely 
showing that the study of large model zeolites does hold predictive value for more industrially relevant zeolite catalysts. Regardless of the alcohol used in the study, the etherification activity was found to decrease with the size of the zeolite particle (Table 1). The conversion of $1,2 \mathrm{PG}$ decreased from $71 \%$ after $3 \mathrm{~h}$ of reaction to $30 \%$ after $5 \mathrm{~h}$ of reaction when the zeolite with a particle size of $9 \mu \mathrm{m}$ was used instead of $0.5 \mu \mathrm{m}$ one (Table 1). Following the same trend, the conversion of glycerol dropped from $14 \%$ to $11 \%$ and $2 \%$ upon increasing the zeolite crystal particle size from 0.1 to $0.5 \mathrm{~nm}$ and $9 \mu \mathrm{m}$, respectively.

$\mathrm{X}$-ray photoelectron spectroscopy (XPS) measurements indicated an inhomogeneous distribution of $\mathrm{Al}$ in the zeolite crystal that becomes more evident with increasing the size of the zeolite crystal (Table 1). The concentration of Al was observed to be higher at the surface of the zeolite compared to the bulk value (Table 1), in agreement with previous reports on other zeolites. ${ }^{11 a, 24,25}$ The distribution of $\mathrm{Al}$ in the framework of the zeolite influences the hydrophilic properties of the zeolite and, therefore, the interaction with the reactants. This together with the particle size influences the extent of the observed zeolite deactivation. It is known that internal diffusion limitation often occurs in large zeolite crystals, which enhances the deactivation due to slow release of the coke type molecules. ${ }^{15,21}$ For H-Beta (12.5), which presents both a small Si/Al ratio (12) at the surface and the smallest particle size, deactivation is less pronounced than for the H-Beta (45), for instance. Thermogravimetric analysis (TGA) of the spent catalysts recovered from a 1,2PG etherification reaction with 1-octene (Supporting Information Figure 9) indicated that $15 \mathrm{wt} \%$ coke was deposited on the H-Beta (40.5) catalyst, where a weight loss of just $11 \%$ was obtained for H-Beta (12.5). A comparison of the amount of coke formed during the etherification of glycerol and 1,2PG with 1-octene over H-Beta (12.5) catalyst by TGA analysis of the spent catalyst showed a weight loss of $20 \%$ for glycerol compared to $11 \%$ with 1,2-PG. The FT-IR and DR UV-vis measurements again confirm the presence of soft coke species of the polyolefinic type, as previously observed with the model zeolites (Figure 8 and Figure 9 of Supporting Information). Also the textural properties of the zeolite were affected by the coke. The surface area and the micropore volume of the spent catalysts decreased compared to the fresh zeolites (Table 1 in Supporting Information). For H-Beta (12.5) recovered from the glycerol etherification reaction, the micropore volume decreased from 0.19 to $0.03 \mathrm{~cm}^{3} / \mathrm{g}$ and the surface area from 571 to $280 \mathrm{~m}^{2} / \mathrm{g}$ corresponding with the strong deactivation of the catalyst after $5 \mathrm{~h}$ of reaction. Similarly, the surface area of H-Beta (12.5) recovered from the etherification of 1,2PG with 1-octene decreased to $303 \mathrm{~m}^{2} / \mathrm{g}$ and the micropore volume to $0.07 \mathrm{~cm}^{3} / \mathrm{g}$ after $5 \mathrm{~h}$ of reaction, whereas after just $3 \mathrm{~h}$ of reaction the BET surface area was $500 \mathrm{~m}^{2} / \mathrm{g}$ and the micropore volume $0.14 \mathrm{~cm}^{3} /$ g. These values, combined with the information obtained from the TGA experiments, indicate that the degree of pore blockage by coke is $67 \%$ for the zeolite taken from glycerol etherification and $31 \%$ for $1,2 \mathrm{PG}$ etherification.

As indicated by the fluorescence microspectroscopic results, there is a difference in the distribution of the alcohol and alkene reactants on the zeolite particle that directly affects its catalytic activity. These observations were confirmed and explained the

(24) Auroux, A.; Dexpert, H.; Leclercq, C.; Vedrine, J. Appl. Catal. 1983, 6, 95-119.

(25) (a) Baldin Cardoso, M. J.; De Oliveira Rosas, D.; Lau, L. Y. Adsorption 2005, 11, 577-580. (b) Chao, K.-J.; Chern, J.-Y. Zeolites 1988, 8, $82-85$.
Table 2. Influence of Alkene Chain Length on the Etherification of Alcohols over Powdered H-Beta (12.5) ${ }^{a}$

\begin{tabular}{clcccc}
\hline alcohol & \multicolumn{1}{c}{ alkene } & conv $(\%)$ & sel $_{\text {monoether }}(\%)$ & sel $_{\text {diether }}(\%)$ & sel other $_{(\%)}$ \\
\hline glycerol & 1-hexene & 35 & 97 & & 3 \\
& 1-octene & 16 & 83 & 6 & 9 \\
\multirow{2}{*}{$1,2 \mathrm{PG}$} & 1-dodecene & 7 & 72 & 10 & 8 \\
& 1-hexene & 56 & 55 & 40 & 5 \\
& 1-octene & 76 & 82 & 6 & 9 \\
& 1-dodecene & 71 & 93 & 3 & 3
\end{tabular}

${ }^{a}$ Etherification conditions: $0.5 \mathrm{~g}$ catalyst, $5 \mathrm{~h}, 413 \mathrm{~K}$, alkene/alcohol molar ratio 3:1, $0.05 \mathrm{~mol}$ alcohol, $10 \mathrm{bar}$ Ar.

Table 3. Pretreatment Effect on the Activity of H-Beta Zeolites in the Etherification of $1,2 \mathrm{PG}$ with 1 -Octene ${ }^{a}$

\begin{tabular}{clccc}
\hline$S_{\text {ext }}\left(\mathrm{m}^{2} / \mathrm{g}\right)$ & catalyst & conv $(\%)$ & sel $_{\text {c8-ether }}(\%)$ & sel other $(\%)$ \\
\hline 230 & Beta $(12.5)$ & 76 & 82 & 9 \\
160 & Beta $(12.5)^{b}$ & 27 & 86 & 9 \\
147 & Beta $(12.5)^{c}$ & 7 & 83 & 15 \\
41 & Beta $(45)$ & 30 & 81 & 14 \\
n.d. & Beta $(45)^{d}$ & 25 & 83 & 7
\end{tabular}

${ }^{a}$ Etherification conditions: $0.5 \mathrm{~g}$ catalyst, $5 \mathrm{~h}, 413 \mathrm{~K}$, 1-octene: 1,2PG, 0.05 mol 1,2PG, 10 bar Ar. ${ }^{b} 4$ wt $\% \mathrm{SiO}_{2} .{ }^{c} 8$ wt $\% \mathrm{SiO}_{2}$. ${ }^{d}$ Calcined for $1 \mathrm{~h}$ at $400{ }^{\circ} \mathrm{C}$.

differences in the etherification activity of $\mathrm{H}$-Beta zeolites for various alcohols such as glycerol and 1,2PG. Further confirming the spectroscopic observations are the catalytic results obtained with H-Beta (12.5) for the etherification of glycerol and 1,2PG with various alkenes. For the etherification of 1,2PG with 1 -octene conversion was $76 \%$, whereas for 1-dodecene conversion was just $71 \%$ after the same reaction time (Table 2), which is in line with the fluorescence measurements. For glycerol etherification the activity of H-Beta (12.5) decreases with the length of the linear alkene. The highest conversion $(35 \%)$ was observed with 1-hexene and the lowest $(\sim 8 \%)$ with 1-dodecene (Table 2). On the basis of the fluorescence data these results can be easily understood, as both 1-hexene and glycerol presented a similar distribution inside the zeolite particle resulting in a more pronounced interaction. In the case of 1-dodecene, on the other hand, the alkene will not have access to the alcohol molecules. Also, for the etherification of 1,2PG with 1-hexene, a lower conversion was obtained (56\%) compared with those obtained for 1-octene and 1-dodecene (Table $2)$. This is again in line with the spectroscopic measurements since 1-hexene and 1,2-PG were found to have a different adsorption mode on the large H-Beta (45) zeolite crystals.

External Surface Modification of the H-Beta Zeolites. The confocal fluorescence measurements clearly indicated that the etherification process is mainly taking place on the external surface of the zeolite. Deactivation of the zeolite is then caused by the blockage of its external surface by coke molecules that are mainly formed by the alkene. In order to further corroborate these microspectroscopic observations with actual catalytic activities, the H-Beta zeolites were pretreated in order to modify the external and internal surface and subsequently tested in the etherification reaction (Table 3). Recently, the group of Lerch$\mathrm{er}^{18}$ reported that creating an amorphous silica layer on the external surface of the zeolite particle highly increased the diffusion of the reactants to the center of the grain and improved the catalytic activity. We followed the reported procedure and prepared samples with 4 and 8 wt \% silica on H-Beta (12.5) (see Supporting Information Figure 3). The etherification activity of the resulting materials was compared to that of the parent zeolite materials (Table 3). A decrease of the external surface 
area of the zeolite from 230 to $147 \mathrm{~m}^{2} / \mathrm{g}$ was observed after the TEOS treatment for the $8 \mathrm{wt} \% \mathrm{SiO}_{2}-\mathrm{H}$-Beta (12.5). At the same time the XPS measurements indicated that no $\mathrm{Al}$ is present on the external surface of the zeolite, as it is probably covered by a pure silica layer (see Supporting Information Figure 1d). The etherification activity of these silica treated zeolites dropped significantly compared to the parent material (Table 3). Almost no $1,2 \mathrm{PG}$ conversion $(7 \%)$ was obtained for $8 \mathrm{wt} \% \mathrm{SiO}_{2}-\mathrm{H}-$ Beta (12.5). The 4 wt $\% \mathrm{SiO}_{2}-\mathrm{H}$-Beta (12.5) presented a higher conversion $(27 \%)$ but still considerably less than the one obtained with untreated H-Beta (12.5) (76\%). The selectivity for the C8-ether remained above $80 \%$ in the series, but the selectivity to the byproduct increased to $15 \%$ for $8 \mathrm{wt} \% \mathrm{SiO}_{2}-$ $\mathrm{H}$-Beta zeolite. This indicates that the blockage of the external surface and the decrease of its Al content (and concomitant reduction of the number of available Brønsted acid sites on the surface) are detrimental to the etherification activity of the zeolite. Furthermore, blockage of the internal surface while keeping the available external surface the same turned out to have little effect on catalytic activity. This was exemplified in the etherification of $1,2 \mathrm{PG}$ by using a partially calcined zeolite. The as-synthesized H-Beta (45) was partially calcined by keeping it at $400{ }^{\circ} \mathrm{C}$ for $1 \mathrm{~h}$. After this treatment, the resulting dark brown catalyst now still has its pores blocked by partially decomposed template molecules ${ }^{11 a}$ (see Supporting Information Figure 6). This catalyst was also tested in the etherification of 1,2PG with 1-octene. The carbonaceous template-derived species that are formed on the external surface of the zeolite apparently are readily washed away by 1 -octene, as the external surface is again available for the etherification reaction. Indeed, by comparing the etherification activity with that of the calcined zeolites, it can be observed that similar conversions and selectivities were obtained (Table 3).

\section{Conclusions}

We have demonstrated with the use of confocal fluorescence microscopy and bulk spectroscopic techniques (FT-IR and DR UV-vis) the cause of catalyst deactivation in the direct etherification of biomass-based alcohols with long linear alkenes under solvent-free conditions. More specifically, confocal fluorescence microscopy proved very useful in understanding the catalytic activity of commercial zeolites at the level of an individual catalyst particle by following the etherification process on an H-Beta zeolite with crystal size of $9 \mu \mathrm{m}$ as model catalyst. This allowed us to observe the interaction between the reactants (alcohols and alkenes) and the catalyst in a space-resolved manner. It was found that the etherification of alcohols with long linear alkenes takes place on the external surface of the zeolite. Alkenes were found mainly responsible for the formation of coke-like species and blocking of the external surface, which led to the partial or total loss of catalyst activity, an observation further confirmed by other characterization techniques, such as FT-IR, DR UV-vis, TGA, and $\mathrm{N}_{2}$ adsorption. A large external surface area having a high concentration of framework aluminium was found to be essential for a high etherification activity. The high etherification activity obtained for glycols and particularly for 1,2-propylene glycol with 1-octene and 1-dodecene is due to the fact that both the alcohol and the alkene are preferentially interacting with the external zeolite surface. Therefore, the reactants are in close contact and easily transform into reaction products and act as solvents for the desorption of the products. The pronounced deactivation observed for glycerol etherification is determined by the different mode of adsorption of this alcohol. Glycerol reacts on the active sites present into the center of the zeolite crystal, whereas the alkene, on the other hand, interacts with the active sites from the external surface. Using a shorter alkene, such as 1-hexene, which interacts with the zeolite in the same manner as glycerol, higher conversions could indeed be obtained. Finally, the etherification reaction studied here can be seen as an example typical for a biomass conversion process in the liquid phase, where the physicochemical properties of the reactants strongly influence the activity and stability of the heterogeneous catalyst.

Acknowledgment. The authors thank the ACTS-ASPECT program for funding this project. E.S. is thankful to the NWO for his Veni grant, and B.M.W. acknowledges funding from NWOCW (Top Grant) and NRSC-C.

Supporting Information Available: Catalyst characterization data (XRD, XPS, SEM), FT-IR, and DR UV-vis measurements, textural properties data of spent catalyst, confocal fluorescence microscopy images, and videos. This material is available free of charge via the Internet at http://pubs.acs.org.

JA102566B 